\title{
Experimental Study on the Mechanics Characteristics of CFRP Strengthening of Highway Tunnels at Different Damage States
}

\author{
Xuezeng Liu $\mathbb{D}^{1}{ }^{1}$ Yunlong Sang $\mathbb{D}^{2,3}$ Shuang Ding $\mathbb{D}^{2,4}$ Guiliang You, ${ }^{5}$ Wenxuan Zhu, \\ Ruoyang Zhou, ${ }^{7}$ Qiang Wei, ${ }^{8}$ and Liang Jiang ${ }^{8}$ \\ ${ }^{1}$ Tongji University, Shanghai 200092, China \\ ${ }^{2}$ Shanghai Tongyan Civil Engineering Technology Co., Ltd., Shanghai 200092, China \\ ${ }^{3}$ Civil Engineering Center of Ministry of Education Information Technology, Tongji University, Shanghai 200092, China \\ ${ }^{4}$ Shanghai Engineering Research Center of Underground Infrastructure Detection and Maintenance Equipment, \\ Shanghai 200092, China \\ ${ }^{5}$ Huadu District Transportation Bureau, Guangzhou 510800, China \\ ${ }^{6}$ Nagoya Institute of Technology, Nagoya 466-8555, Japan \\ ${ }^{7}$ China State Construction Engineering Corporation, Beijing 10029, China \\ ${ }^{8}$ Gui Zhou Expressway Group Co.Ltd., Guiyang 550001, China
}

Correspondence should be addressed to Shuang Ding; dingshuang525@hotmail.com

Received 9 October 2020; Revised 25 November 2020; Accepted 8 December 2020; Published 19 December 2020

Academic Editor: Chun Zhu

Copyright (C) 2020 Xuezeng Liu et al. This is an open access article distributed under the Creative Commons Attribution License, which permits unrestricted use, distribution, and reproduction in any medium, provided the original work is properly cited.

Cracks and other diseases may occur in the long-term operation of highway tunnels and reduce the structural load-carrying capacity. Strengthening using carbon fiber reinforced polymer (CFRP) sheets and other materials could extend the service time of the tunnels. However, the process of strengthening tunnels is remarkably different from the process of strengthening aboveground structures because of the secondary load. In order to understand the development of stress and deformation of strengthened tunnels under secondary load, a 1:10 scaled model was tested to simulate the tunnel strengthened with CFRP under different damage states. The test results show that CFRP strengthening improved the stiffness of the structure and inhibited the propagation of the existing cracks. The peeling of the CFRP sheets made the strengthened structure quickly lose its load-carrying capacity, causing the instability of the structure. The failure loads of the structures strengthened at different damage states were essentially the same, with an average value of $184 \%$ of the original failure load. Nevertheless, the early strengthening helped control the structural deformation. The test results also demonstrate that the bonding strength between the CFRP and the lining is essential for strengthening effectiveness. This study provides a theoretical basis for similar engineering reinforcement designs.

\section{Introduction}

Lining cracking is one of the most common structural problems for highway tunnels. In particular, the developing cracks caused by external loads not only reduce the effective cross-sectional area of reinforced concrete members and lower the structural load-carrying capacity but also offer a pathway for groundwater to invade the tunnel, causing steel corrosion and material deterioration as well as aggravating the structural deformation and crack propagation [1-4]. Timely strengthening is needed in order to prevent cracks from forming during development, regain the load-carrying capacity, and extend the service time of the tunnels.

The carbon fiber reinforced polymer (CFRP) sheet has been widely used to strengthen tunnels due to its many advantages, such as high tensile strength, good deformation adaptability, a small footprint, and construction convenience $[3,5]$. A number of research studies have been conducted in order to establish the computational models and elucidate the load-carrying mechanisms of CFRP-strengthened structures. Luo [6] proposed a theoretical calculation method specifically intended for the CFRP-strengthening of highway 
tunnel lining structures. Li et al. [7] numerically simulated the characteristics of the load-carrying compatibility between CFRP and subway tunnel linings. Jia and Nie [8] carried out bending tests and a finite element analysis of simply supported reinforced concrete beams in order to study the effectiveness of different CFRP wrapping options for repairing the lining segments that were experiencing freeze-thaw damage. Li et al. [9] carried out model tests on the damaged shield segment structures strengthened by CFRP grids and obtained the failure modes of a bonding surface created using different bonding techniques. Sahranavard and Aghanoori [10] conducted in situ monitoring of the CFRP-strengthened damaged lining of the Haji-Abad tunnel in Iran and concluded that CFRP strengthening met the load-carrying requirements under the design-level loads.

The process of strengthening tunnels is remarkably different from the process of strengthening aboveground structures. This is because tunnel structures are buried in the ground, and they are difficult to unload during the strengthening process. The disturbance and deterioration of the surrounding rock during the strengthening and operation of the structure lead to an increase in the tunnel's external load, which is referred to as the secondary load problem faced by strengthened structures. Thus far, research dealing with the deformation and damage of strengthened structures under secondary load has been scarce. Jia and Nie [8] considered the effects of a secondary load using a simply supported beam model, but they ignored the constraint of the surrounding rock and the overall force compatibility of the structure. Because the field data collected from real-world projects can only reflect the strengthening effectiveness under a design-level load, the damage processes of strengthened structures under an increasing load, as well as the effectiveness of the strengthening conducted at different original damage levels, are still not clearly known. Therefore, model tests should also be carried out to enable further investigation.

Field survey data for structural damages and disasters show severe cracks in linings surrounded by weak, fragmentary rock. Under this geological condition, the external load acting on the lining is mainly the loose load of the arch, and it is affected by factors such as the rainfall and the surrounding rock deterioration. Additionally, the loose zone of the arch tends to expand due to long-term operation, thereby increasing the load level, inducing new cracks or widening existing ones, causing water leakage and other problems [1], and hence posing a huge threat to operational safety $[11,12]$. To resolve this problem, this study tested a $1: 10$ scale physical similitude model, which represents a highway tunnel constructed in the grade VI soft fragmentary surrounding rock. The deformation and failure processes of CFRP-strengthened reinforced concrete linings with different original damage states under a loose load were investigated. The failure modes and the failure loads of strengthened structures were analyzed, and the effectiveness of CFRP strengthening at different original damage states and the factors affecting this effectiveness were examined. Reliable test data are provided for the CFRP-strengthening design of damaged linings. Different from the similar tests, both the secondary load conditions of the strengthened structure and the constraint of the surrounding rock were considered in this study, which made the results closer to the actual engineering project. In addition, this paper compares the effect of different strengthening timing for the first time, and the design suggestions were given in the conclusion.

\section{Similitude Model Test Protocol}

2.1. Test Device Design. For large-size structures, the cost and difficulty of making test pieces in real size are high. Reducedscale model test thus become a commonly used method in civil engineering experiments [13-15], especially in geotechnical [16-18] and underground engineering [19]. The authors developed a circumferential loading device that included a tunnel model, a jack loading system, a straindisplacement measurement system, a spring system that simulated the resistance of the surrounding rock, and a reaction frame, as shown in Figure 1:

The tunnel model was a reinforced concrete lining with an inverted arch. Only the secondary lining structure was considered. The jack loading system consisted of 11 independently controllable jacks. The measurement range of each single jack was $30 \mathrm{~N}$ to $5000 \mathrm{~N}$, which was distributed by a load plate as a uniform load of $0.48 \mathrm{kPa}$ to $80.9 \mathrm{kPa}$. The elastic resistance of the surrounding rock was simulated through the spring, the reaction frame, and the passively loaded jacks. The measurement system consisted of dial indicators, strain gauges, automatic acquisition instruments, and digital cameras that were used to observe the structural deformation, crack, and strain development in real time.

The test focused on the analysis of the deformation and failure processes of the CFRP-strengthened liners under an external load, while the self-weight was ignored. To facilitate the test operation, the device was placed horizontally, as shown in Figure 1(a).

\subsection{Tunnel Prototype and Model Design}

2.2.1. Tunnel Prototype. The prototype tunnel has a cross section that is $1186 \mathrm{~cm}$ wide, $962.8 \mathrm{~cm}$ tall, and $300 \mathrm{~cm}$ long axially. The secondary lining is made of reinforced concrete with a thickness of $50 \mathrm{~cm}$ and standard compressive strength of $30 \mathrm{MPa}$, and the steel rebar is with yield strength of $335 \mathrm{MPa}$. The reinforcement ratio is $0.62 \%$. The elastic resistance coefficient $k$ of the surrounding rock is between $0 \mathrm{MPa} / \mathrm{m}$ and $60 \mathrm{MPa} / \mathrm{m}$.

2.2.2. Similitude Ratios. Taking into account the test purpose, laboratory conditions, and the ease of operation, it was determined that the geometric similitude ratio of the prototype to the model, $C_{L}$, was 10 , the elastic modulus similitude ratio $C_{E}$ and the stress similitude ratio $C_{\sigma}$, which were both measured in accordance with the indoor scaled test, were 10 and 20, respectively. The similitude law and the dimensional analysis method were used to determine the similitude ratios for other key physical quantities, as shown in Table 1. 


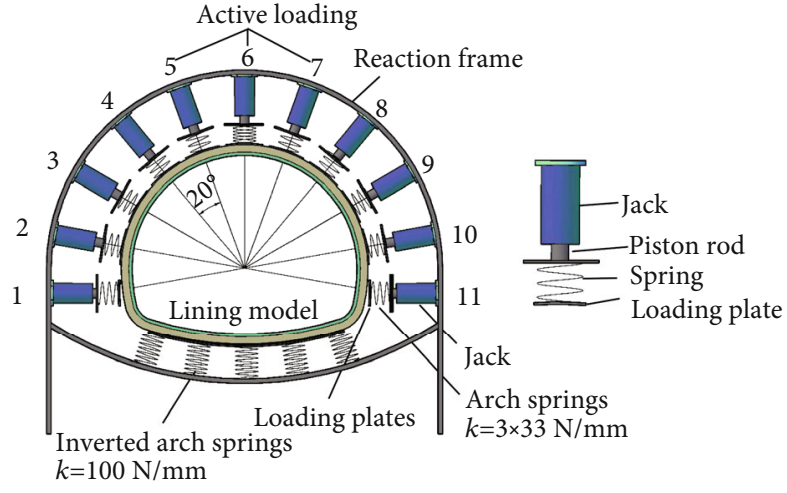

(a) Schematic diagram of test devices

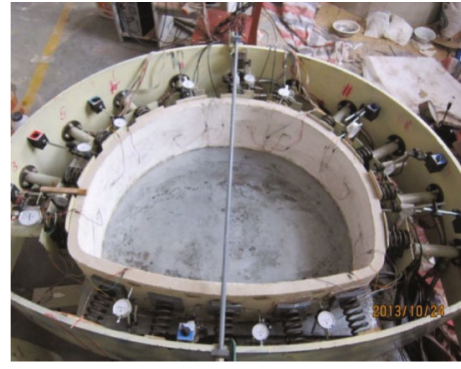

(b) Horizontally positioned model and equipment

FIgURe 1: Test devices.

TABLE 1: Similitude ratios of physical quantities.

\begin{tabular}{|c|c|c|c|}
\hline Physical quantity & Unit & Similar relationship & Similar constant $C$ \\
\hline Length $L$ & $\mathrm{~m}$ & $C_{L}=L_{\text {prototype }} / L_{\text {mod el }}$ & 10 \\
\hline Stress $\sigma$ & $\mathrm{N} / \mathrm{m}^{2}$ & $C_{\sigma}=\sigma_{\text {prototype }} / \sigma_{\text {mod el }}$ & 10 \\
\hline Elastic modulus $E$ & $\mathrm{~N} / \mathrm{m}^{2}$ & $C_{E}=E_{\text {prototype }} / E_{\text {mod el }}$ & 20 \\
\hline Displacement $\delta$ & $\mathrm{m}$ & $C_{\delta}=\delta_{\text {prototype }} / \delta_{\text {mod el }}=C_{\sigma} C_{L} / C_{E}$ & 5 \\
\hline Plane force $s$ & $\mathrm{~N} / \mathrm{m}^{2}$ & $C_{s}=s_{\text {prototype }} / s_{\text {mod el }}=C_{\sigma}$ & 10 \\
\hline Strain $\varepsilon$ & “1” & $C_{\varepsilon}=\varepsilon_{\text {prototype }} / \varepsilon_{\text {mod el }}=C_{\sigma} / C_{E}$ & 0.5 \\
\hline Poisson ratio $\mu$ & “1” & - & 1 \\
\hline Volume force $\rho$ & $\mathrm{N} / \mathrm{m}^{3}$ & $C_{\rho}=\rho_{\text {prototype }} / \rho_{\text {mod el }}=C_{\sigma} / C_{L}$ & 1 \\
\hline Force $N$ & $\mathrm{~N}$ & $C_{N}=\left(N_{\text {prototype }} / N_{\text {mod el }}\right) C_{\sigma} C_{L}^{2}$ & 1000 \\
\hline Bending moment $M$ & $\mathrm{~N} \cdot \mathrm{m}$ & $C_{M}=M_{\text {prototype }} / M_{\text {mod el }}=C_{\sigma} C_{L}^{3}$ & 10000 \\
\hline Elastic resistance coefficient $k$ & $\mathrm{~N} / \mathrm{m}^{3}$ & $C_{k}=k_{\text {prototype }} / k_{\text {mod el }}=C_{\sigma} / C_{\delta}$ & 2 \\
\hline
\end{tabular}

2.2.3. Similitude Model Development. Based on the geometric similitude ratio, the tunnel model had a lining thickness of $5 \mathrm{~cm}$, a width of $118.6 \mathrm{~cm}$, a height of $96.28 \mathrm{~cm}$, and an axial direction of $30 \mathrm{~cm}$, as shown in Figure 2(a).

The model used mixed mortar materials with wire mesh to simulate the reinforced concrete. The mixed mortar was made of cement, yellow sand, lime paste, and water in a specific mass proportion of $1: 7.75: 0.60: 1.76$. The uniaxial compression test of the cubic specimen made in the above mortar ratio shows that the elastic modulus of the model material is $1.57 \mathrm{GPa}$ and it has a similitude ratio of approximately 20 , and the compressive strength is $3.1 \mathrm{MPa}$ and it has a similitude ratio of 10 , generally meeting the requirements.

The steel wire mesh material was the same as the prototype steel rebar. The amount of reinforcement was determined according to the similitude of the bending stiffness of the lining section, and the similitude ratio of the reinforcement ratio is 10 . The cross section of the model with reinforcement is shown in Figure 2(b). The reinforcement ratio is $0.069 \%$, essentially meeting the similitude ratio requirement.
The elastic resistance of the surrounding rock is a feature that distinguishes tunnels from above-ground structures. According to Winker's local deformation theory [20], the elastic resistance is proportional to the structural deformation. Springs and hydraulic jacks were used to simulate the elastic resistance of the surrounding rock, and they were selected based on the device size and indoor testing. Specifically, three springs were connected in parallel, each with a stiffness of $33 \mathrm{~N} / \mathrm{mm}$, in order to simulate the arch and sidewalls. The inverted arch was simulated using a single spring with a stiffness of $100 \mathrm{~N} / \mathrm{mm}$. The elastic resistance coefficient of the model was $1.58 \mathrm{MPa} / \mathrm{m}$, and the elastic resistance coefficient of the prototype was $3.16 \mathrm{MPa} / \mathrm{m}$, which is categorized as grade VI surrounding rock.

The focus of the CFRP strengthening simulation is the similitude in tensile strength. Based on indoor testing, it was determined that the aluminum foil fiberglass sheet was used to simulate the CFRP sheet. The tensile strength of the CFRP was $3400 \mathrm{MPa}$ to $5000 \mathrm{MPa}$, and the tensile strength of aluminum foil fiberglass was $405 \mathrm{MPa}$, meeting the requirement of similitude ratios. 


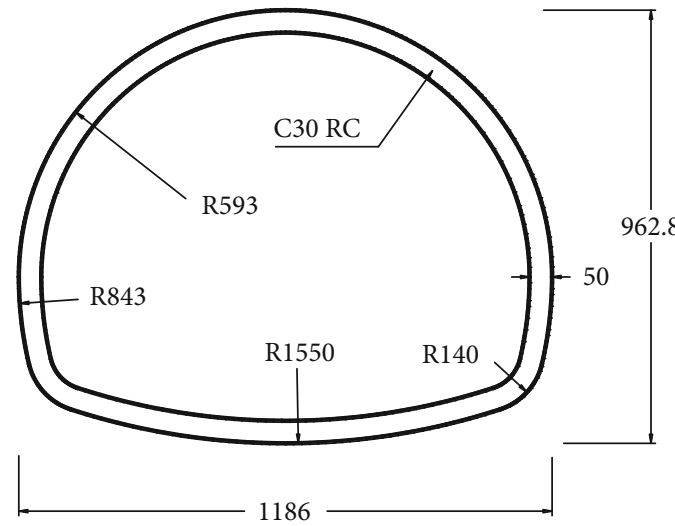

(a) Size of intersecting surface of the tunnel lining model

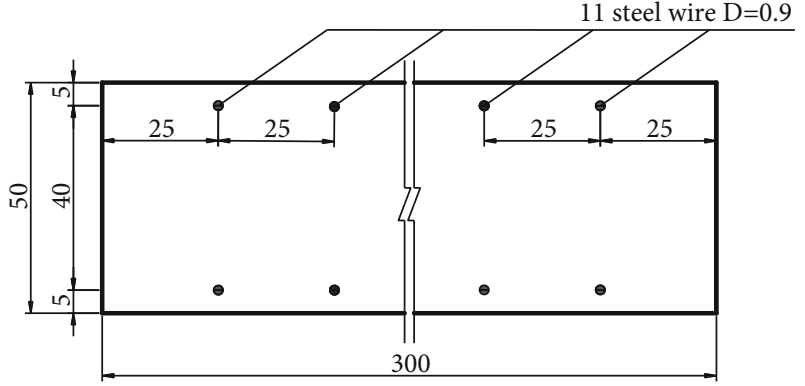

(b) Reinforcement design of the lining model

Figure 2: Model design (unit: $\mathrm{mm}$ ).

2.3. Analysis Conditions. Four different analysis conditions were considered in the tests. Condition 1 was the failure test of the unstrengthened original lining structure. This test was repeated three times to compare the strengthening effectiveness. Conditions 2, 3, and 4 were the tests of the strengthened lining structures using the CFRP sheets of the same parameters at different prestrengthening damage states of the liners. The ratios of the arch load at the time of strengthening to the failure load in condition $1 P_{r} / P_{u 0}$ were $0 \%, 50 \%$, and $90 \%$, respectively.

2.4. Secondary Load Simulation and Measurement Arrangement. Jacks 5, 6, and 7 within the $60^{\circ}$ range of the vault, as shown in Figure 1(a), were controlled, and a monotonic static loading method was used to simulate the loose load at the vault. A force diagram of the structure is schematically shown in Figure 3(a). To simulate the secondary load on the structure, threaded steel rods were added next to the jacks during the strengthening and curing stages to maintain the load. After strengthening, the steel rods were removed and the loading continued. An external load of $0.97 \mathrm{kPa}$ was applied at each increment, and the next incremental load was applied 30 minutes after the stabilization of the last incremental load.

A dial indicator and a strain gauge were placed between every two resistance springs on the surface of the tunnel model to measure the displacement and strain of the tunnel. The arrangement of the dial indicators and strain gauges is shown in Figures 3(b)-3(c).

\section{Test Results and Discussion}

3.1. Deformation and Failure Characteristics of the Original Lining Structure. Unless noted otherwise, the load, displacement, and strain data are for the scaled model. For the sake of convenience, several physical quantities are defined and listed in Table 2.

The data from the three parallel tests under condition 1 are summarized by plotting the vault settlement relative to the springing line and sidewall convergence curves in Figure 4 . It can be seen that the three sets of test data are consistent, demonstrating the reliability of the test results.
Figure 4 shows that under the loose load, the overall stiffness of the original lining structure degraded nonlinearly as the load increased. The deformation and failure processes can be divided into three stages:

(I) Elastic Crack-Free Stage. In this stage, the stress level was low, and thus, the deformation and strain were linearly related. The deformation stiffness associated with the vault settlement $K_{\mathrm{I}}$ was $7.01 \mathrm{kPa} / \mathrm{mm}$. As the external load reached $6.8 \mathrm{kPa}$, the inner side of the vault started to crack

(II) Operational with Cracks Stage. As the load continued to increase, cracks appeared successively in various parts of the lining, with more cracks in the vault and hance, and the major crack was in the vault. The deformation increased rapidly, and the deformation stiffness of the vault further decreased to a $K_{\mathrm{II}}$ value of $1.55 \mathrm{kPa} / \mathrm{mm}$. As the external load reached $18.6 \mathrm{kPa}$, the steel rebars at the major crack position fractured under tension

(III) Accelerated Instability Stage. After the steel rebars at the major crack position fractured, the arch was unstable and the vault settlement increased abruptly. Then, the rebar on the outer side of the hance fractured and the structure became unstable. The failure load $P_{u 0}$ value was $18.9 \mathrm{kPa}$

The failure pattern and fracture distribution of the original lining are sketched in Figure 5, where the solid lines represent the cracks and dashed lines indicate concrete crushing.

The strain distribution over the inner surface of the lining at different load levels is shown in Figure 6(a), where the inward and outward curves denote tension and compression, respectively. The strain distribution is consistent with the loads applied to the structure. Specifically, the inner and outer sides of the vault and the inverted arch were subjected to tension and compression, respectively, and the inner and outer sides of the left and right arches as well as the sidewalls were subjected to compression 


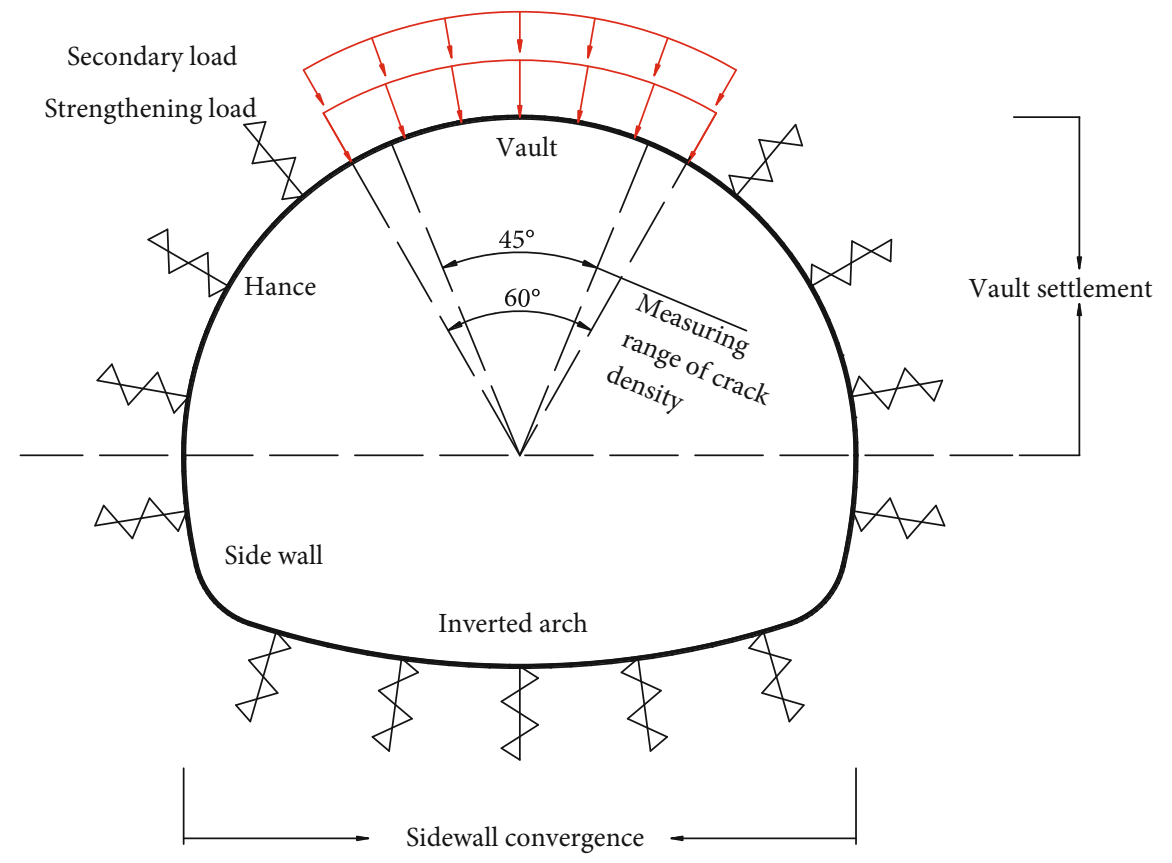

(a) Schematic diagram of structural loading

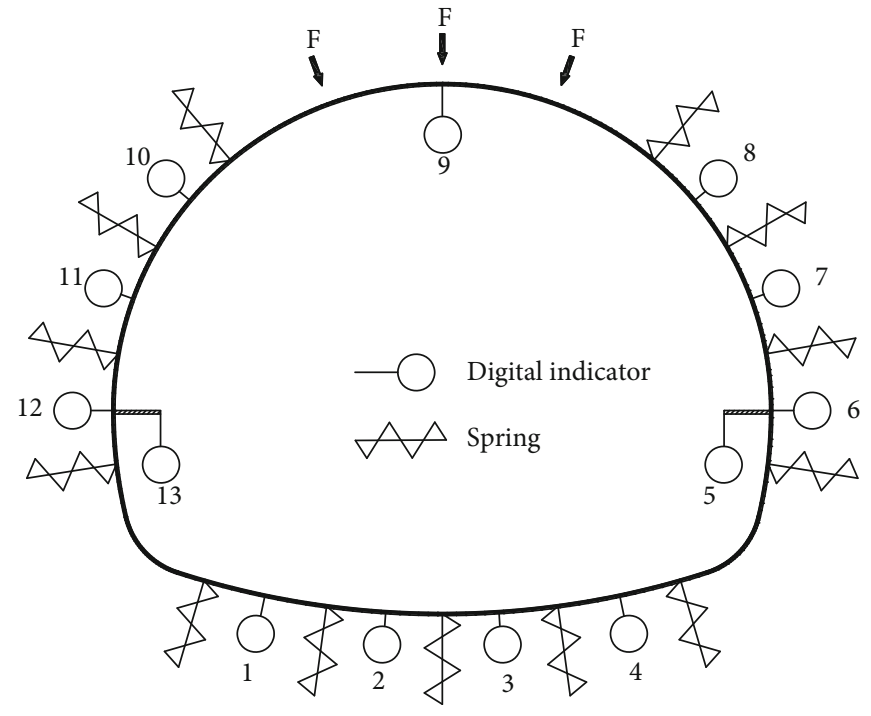

(b) Arrangement of dial indicators

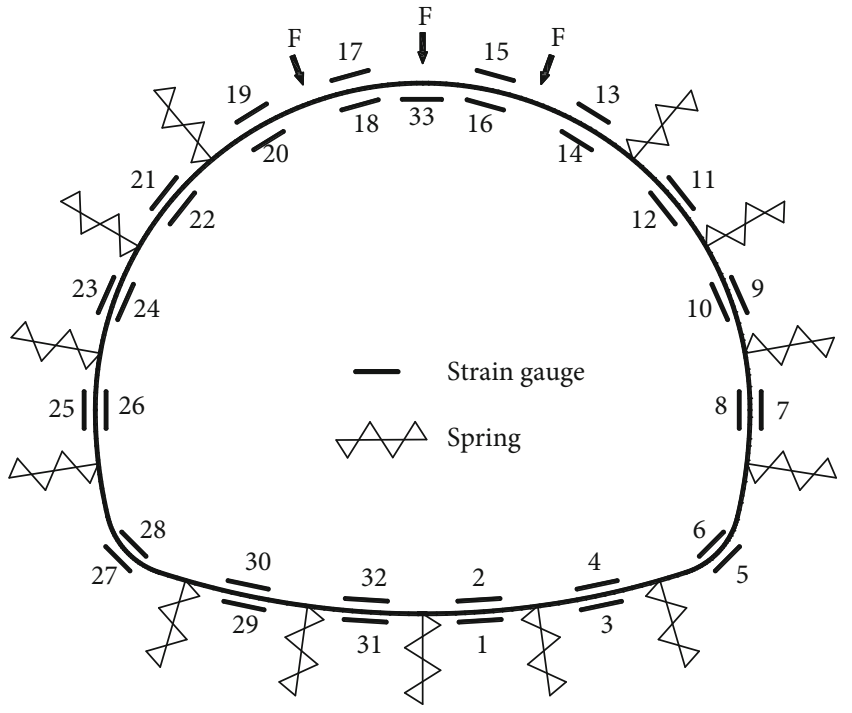

(c) Arrangement of strain gauges

Figure 3: Secondary load simulation and measurement arrangement.

and tension, respectively. Additionally, the strain of the arch was relatively large. The data of strain gauges 16 and 18 of the vault were analyzed. As shown in Figure 6(b), prior to the vault cracking, the strain and load of the vault arch were roughly linearly related. After the load reached $6.80 \mathrm{kPa}$, cracks occurred at the strain gauge locations. As stage II was entered, the strain increased nonlinearly and sharply, and the increase rate was 5 to 10 times that of stage I. In stage III, the arch experienced severe cracking and damage, and the protective layer peeled off, causing the strain gauge to relax and the strain value to drop. Overall, the strain development and distribution were consistent with structural deformation and failure observations.
The experimental data were converted, through similitude ratios, to the responses of the prototype tunnel structure, so that the vault settlement, sidewall convergence, and crack intensity (i.e., crack lengths per unit area within the $45^{\circ}$ center angle of the tunnel vault, as shown in Figure 3(a)) under different load levels could be studied, thereby offering useful information for evaluating the safety of damaged liners, as shown in Table 3.

3.2. Deformation and Failure Characteristics of CFRPStrengthened Structures. CFRP strengthening was carried out in the tests when the arch loads were $0 \%, 49 \%$, and $87 \%$ of the original failure load of the structure, and the 
TABLE 2: Definitions of several physical quantities used in the paper.

\begin{tabular}{|c|c|c|}
\hline Symbol & Definition & Unit \\
\hline$P_{r}$ & Strengthening load & $\mathrm{kPa}$ \\
\hline$P_{c}$ & Cracking load & $\mathrm{kPa}$ \\
\hline$P_{u 0}$ & Failure load of an unstrengthened lining & $\mathrm{kPa}$ \\
\hline$P_{u}$ & Failure load of a strengthened lining & $\mathrm{kPa}$ \\
\hline$K_{\mathrm{I}}$ & Stiffness of an unstrengthened lining at stage I before cracking, as shown in Figure 7 & $\mathrm{kPa} / \mathrm{mm}$ \\
\hline$K_{\mathrm{II}}$ & Stiffness of an unstrengthened lining at stage II after cracking, as shown in Figure 7 & $\mathrm{kPa} / \mathrm{mm}$ \\
\hline$k_{\mathrm{I}}$ & Stiffness of a strengthened lining at the compatible deformation stage, as shown in Figure 8 & $\mathrm{kPa} / \mathrm{mm}$ \\
\hline$k_{\mathrm{II}}$ & Stiffness of a strengthened lining at the rapid deformation stage, as shown in Figure 8 & $\mathrm{kPa} / \mathrm{mm}$ \\
\hline$u$ & Vault settlement during failure & $\mathrm{mm}$ \\
\hline$s$ & Sidewall convergence during failure & $\mathrm{mm}$ \\
\hline
\end{tabular}

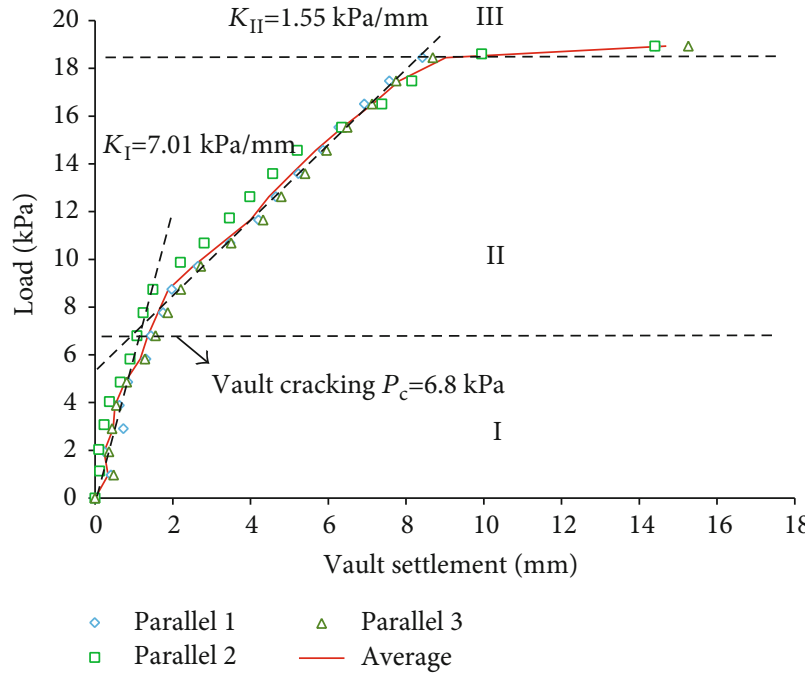

(a) Vault settlement

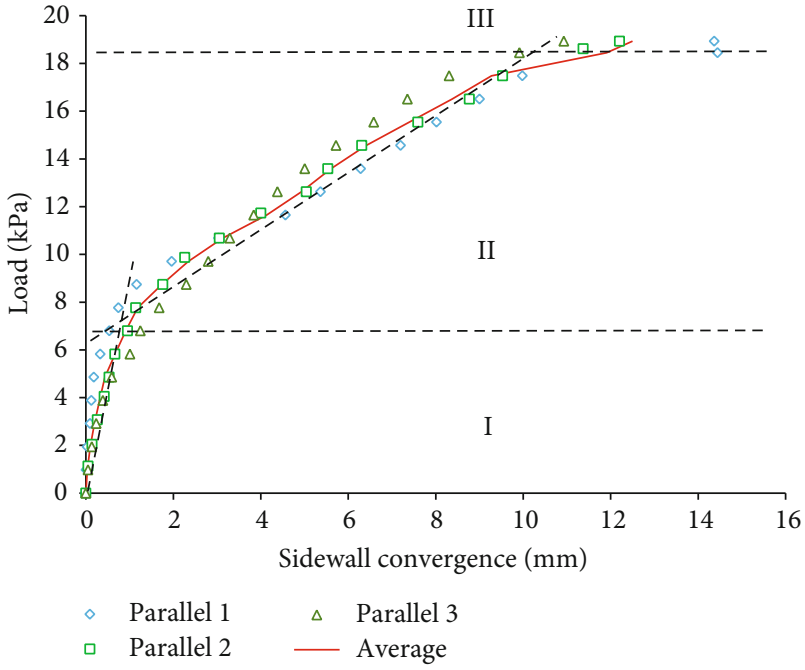

(b) Sidewall convergence

FIGURE 4: Results of parallel tests.

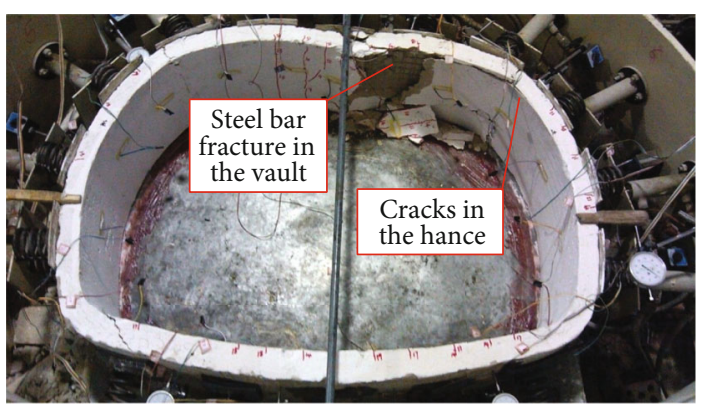

(a) Damage photo
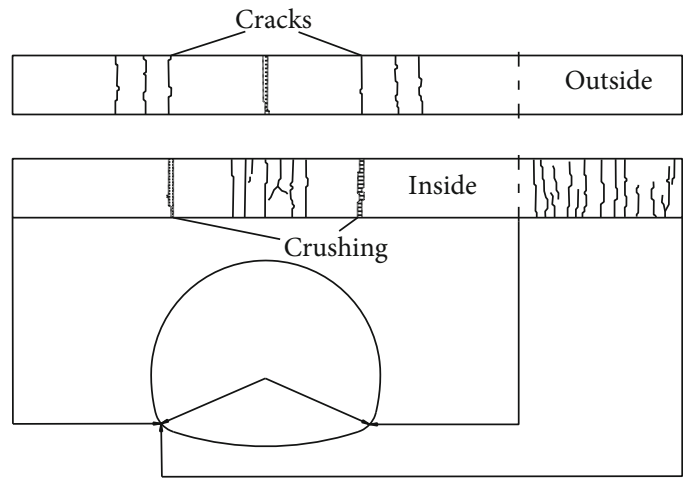

(b) Sketch of fracture distribution

Figure 5: Damage form of the lining under condition 1. 


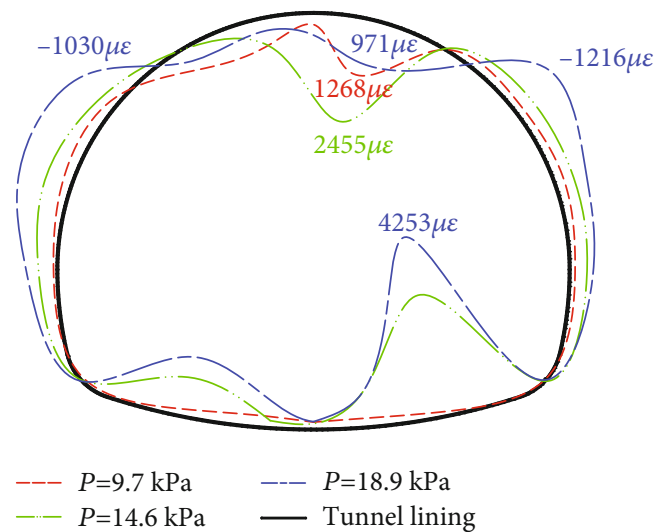

(a) Strain distribution of the inner surface in the lining

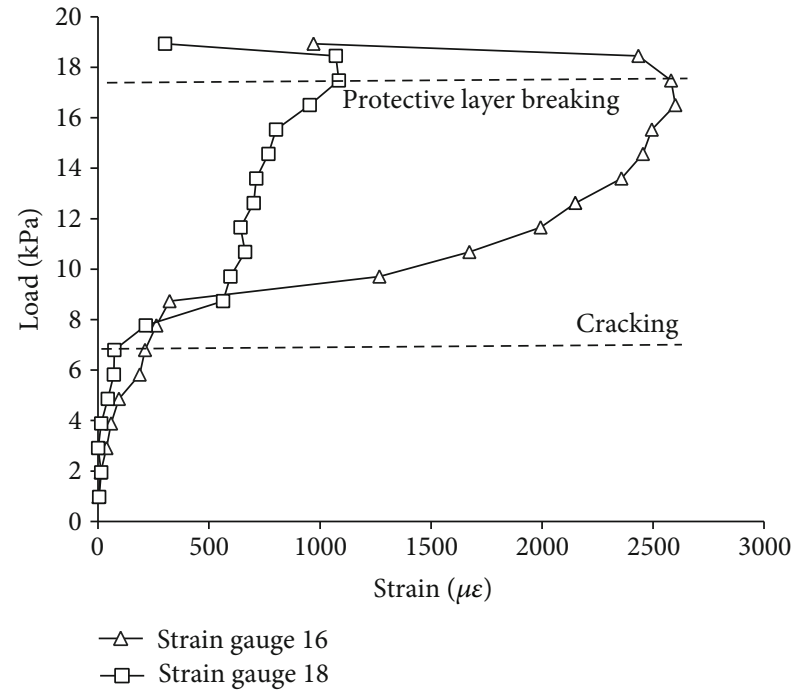

(b) Curves of load-strain in the vault

FIgURE 6: Strain data of the unstrengthened condition $\left(\mu \varepsilon=10^{-6}\right)$.

TABLE 3: The relationship between load, fracture density, vault settlement, and sidewall convergence.

\begin{tabular}{lccc}
\hline $\begin{array}{l}\text { External load } \\
\text { level/failure } \\
\text { load }\end{array}$ & $\begin{array}{c}\text { Crack } \\
\text { density } \\
\mathrm{m} / \mathrm{m}^{2}\end{array}$ & $\begin{array}{c}\text { Vault settlement } \\
\text { of the } \\
\text { prototype/cm }\end{array}$ & $\begin{array}{c}\text { Sidewall } \\
\text { convergence of the } \\
\text { prototype/cm }\end{array}$ \\
\hline $0 \%$ & 0 & 0 & 0 \\
$50 \%$ & 0.585 & 1.33 & 0.88 \\
$70 \%$ & 1.39 & 2.38 & 2.98 \\
$90 \%$ & 1.6 & 3.89 & 4.77 \\
$100 \%$ & 1.6 & 7.20 & 7.19 \\
\hline
\end{tabular}

corresponding loads were $0 \mathrm{kPa}, 9.2 \mathrm{kPa}$, and $16.5 \mathrm{kPa}$, respectively. The structural phenomena prior to strengthening under conditions 3 and 4 were consistent with the one under condition 1, and the load-displacement curves chiefly coincide, as shown in Figure 7, suggesting the reliability of the test data.

Figure 8 shows the variations of the vault settlement and the sidewall convergence before and after the structural strengthening under different conditions. It can be seen that under the secondary load, the deformation and failure processes of the strengthened structure under the three conditions are generally the same and can be divided into 3 stages, namely the coordinated deformation stage, the rapid deformation stage, and the accelerated instability stage.

(I) Compatible Deformation Stage. Because the tensile strength of the CFRP sheets and the shear stiffness of the bonding surface were sufficiently large, the overall stiffness of the structure was enhanced significantly. Taking condition 3 as an example, the deformation stiffness $k_{\mathrm{I}}$ of the vault settlement before cracking was $1.55 \mathrm{kPa} / \mathrm{mm}$, which recovered to $4.21 \mathrm{kPa} / \mathrm{mm}$ after strengthening, representing an increase of $172 \%$. As the external load increased, the CFRP was compatible with the lining in resisting the load, and

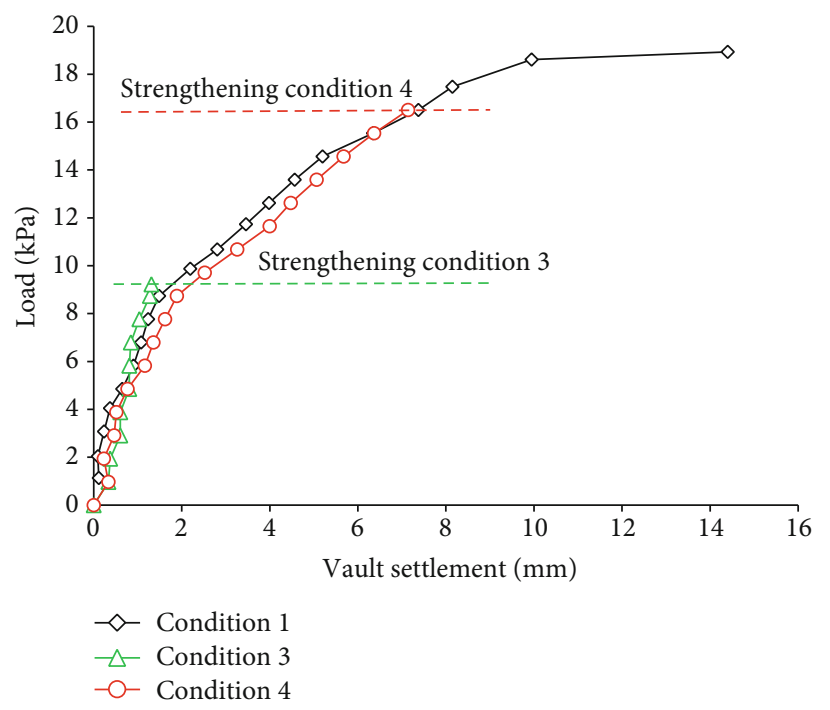

Figure 7: Curves of load-vault settlement with different conditions before strengthening.

the deformation increased linearly and slowly, effectively suppressing the expansion of existing cracks, with new cracks occurring mainly in the hance

(II) Rapid Deformation Stage. As the load continued to increase, the shear stress over the bonding surface increased rapidly, weakening the deformation compatibility between the tunnel and CFRP sheets. The deformation stiffness associated with the vault settlement and the sidewall convergence was rapidly reduced, but they were still higher than the values prior to strengthening. Under condition 3, the deformation stiffness of the vault settlement at this stage was attenuated to a $k_{\text {II }}$ value of $1.63 \mathrm{kPa} / \mathrm{mm}$, which was slightly higher than the $1.55 \mathrm{kPa} / \mathrm{mm}$ 


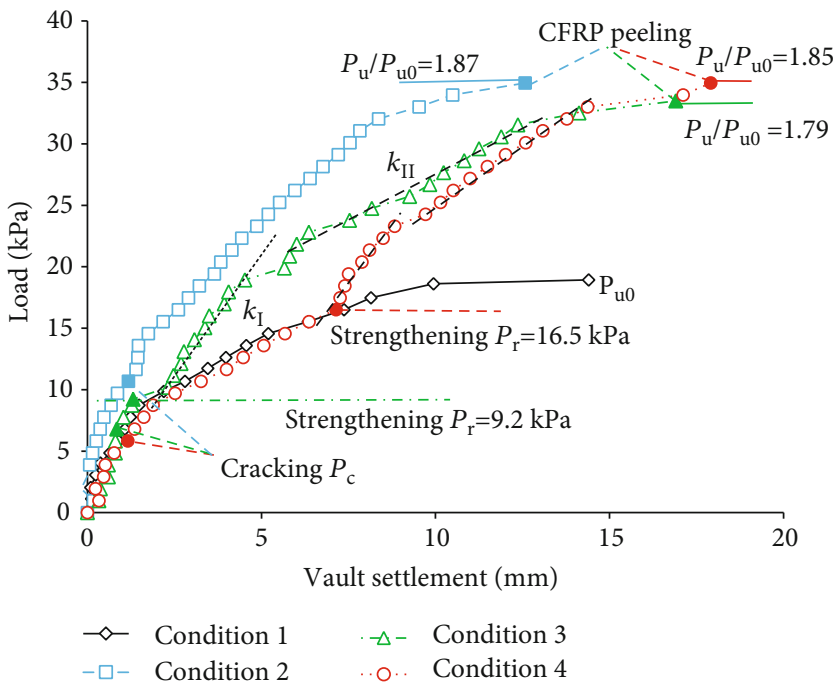

(a) Vault settlement

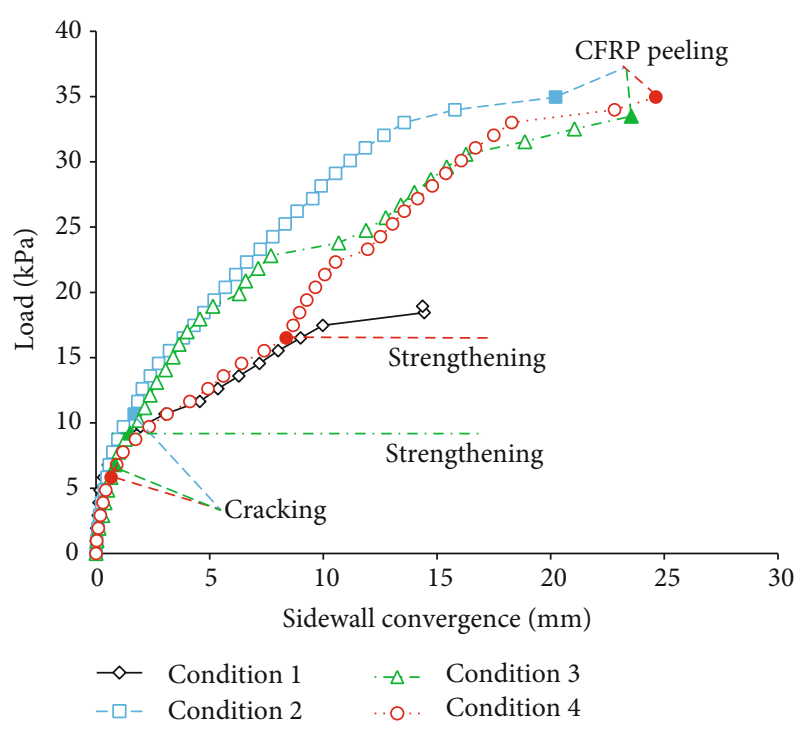

(b) Sidewall convergence

Figure 8: Curves of load-displacement with different conditions.

value of the original structure. At this stage, a number of new cracks appeared at the vault. Due to the presence of the CFRP sheets, the tensile stress over the concrete surface was adjusted continuously, thereby uniformly distributing new cracks, with a density much higher than that observed under condition 1. As this occurred, the existing cracks propagated along the thickness direction

(III) Accelerated Instability Stage. Because the shear stress over the bonding surface cannot be transferred effectively, the deformations of the CFRP sheets and the lining are no longer compatible, causing them to peel off. The lining resists most of the load, the vault settlement increases sharply, and the vault and the hances on both sides fracture successively, demonstrating that the peeling of the CFRP is the key factor that determines the failure of strengthening. The failure mode of the strengthened structure is generally the same as that of the original structure, but the steel rebars on the inner side of the vault do not completely fracture, proving that CFRP sheets resist part of the load

Figure 9 shows the distribution of cracks in the lining after the test under condition 3, as well as the sequences of crack development near $30^{\circ}$ in the left hance, $130^{\circ}$ in the right hance, and $90^{\circ}$ in the vault. In the figure, solid lines denote cracks and the numbers next to cracks represent the load magnitudes $(\mathrm{kPa})$. It can be seen that cracks in the hance occurred mainly at the compatible deformation stage, while those in the vault occurred mainly at the rapid deformation and failure stages.

The relationship between the strain of the CFRP sheets at the vault and the external load is shown in Figure 10. The data for conditions 3 and 4 were measured by strain gauges rearranged after strengthening, so the point associated with zero strain corresponds to the strengthening load. Taking condition 3 as an example, after strengthening, the variation trend of the tensile strain of strain gauge \# 16 was basically consistent with the deformation and damage processes. That is, at the initial stage after strengthening, the original cracks were no longer widened, new cracks mainly appeared in the hance, and the strain slowly increased. After the load reached $22.8 \mathrm{kPa}$, the structure entered the second stage, when the strain of the arch increased faster and new cracks appeared continuously. In the process of increasing the load up to $34.0 \mathrm{kPa}$, the strain of the vault increased to $4013 \mu \varepsilon$ (the ultimate tensile strain of the CFRP is about $20000 \mu \varepsilon$ ), which exceeds the shear strength of the bonding surface between the CFRP sheets and the concrete. The peeling of CFRP sheets from the lining caused the lining to mainly resist the tensile stress on the inner side of the vault, leading to the rapid failure of the vault.

The test data show that the failure load of the structure after strengthening increases significantly. Using condition 3 as an example, the failure load $P_{u}$ is $179 \%$ of that for the strengthened structure.

3.3. Comparison of the Strengthening Effectiveness under Different Damage States. Table 4 summarizes the relevant data for the tests under each condition in this study.

Irrespective of the strengthening at different damage states, the failure of the strengthened structure was always caused by the peeling of CFRP sheets from the lining. After peeling, the vault and hances on both sides fractured successively, causing the structure to fail. Based on the test results, a timely CFRP strengthening prior to vault failure can significantly improve the failure load, which is essentially the same for the strengthening at different damage states. Specifically, the failure loads of conditions 2,3 , and 4 are $35.4 \mathrm{kPa}$, $34.0 \mathrm{kPa}$, and $35.0 \mathrm{kPa}$, respectively, with the largest difference being only $1.4 \mathrm{kPa}$. Considering the range of the test error, the failure load after strengthening is on average $84 \%$ higher than that of the original structure. 


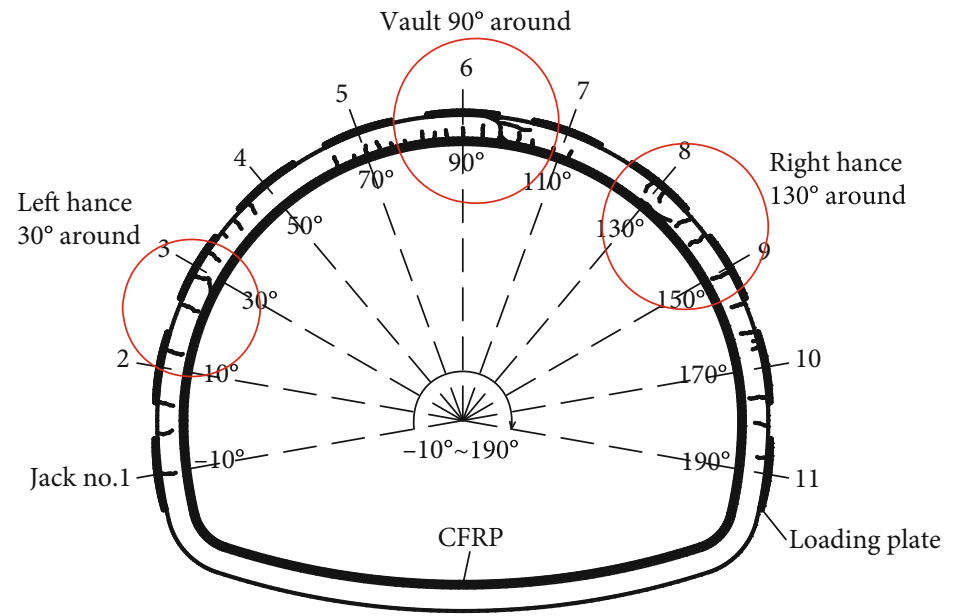

(a) Overall distribution

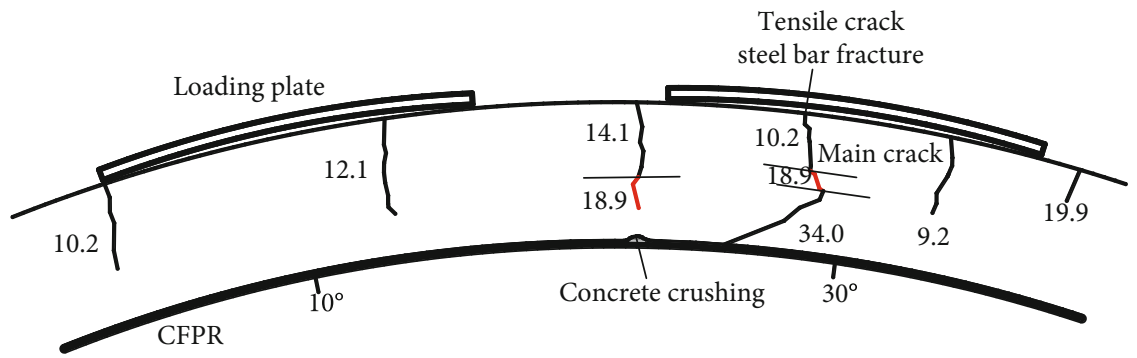

(b) Near $30^{\circ}$ in the left hance

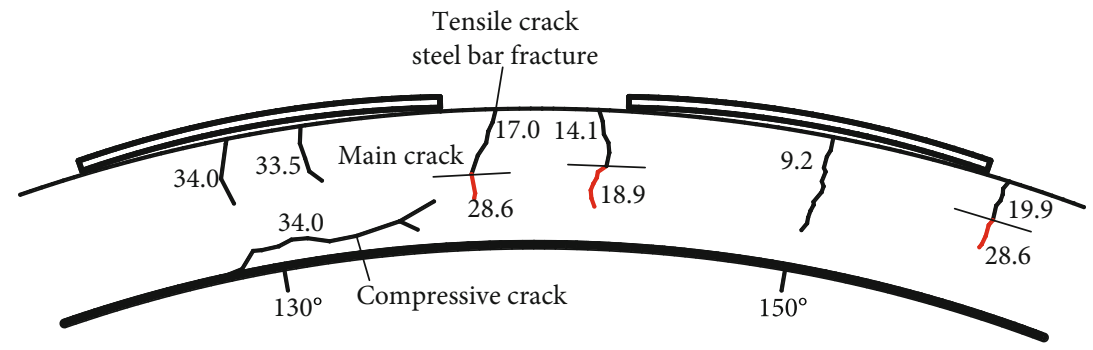

(c) Near $130^{\circ}$ in the right hance

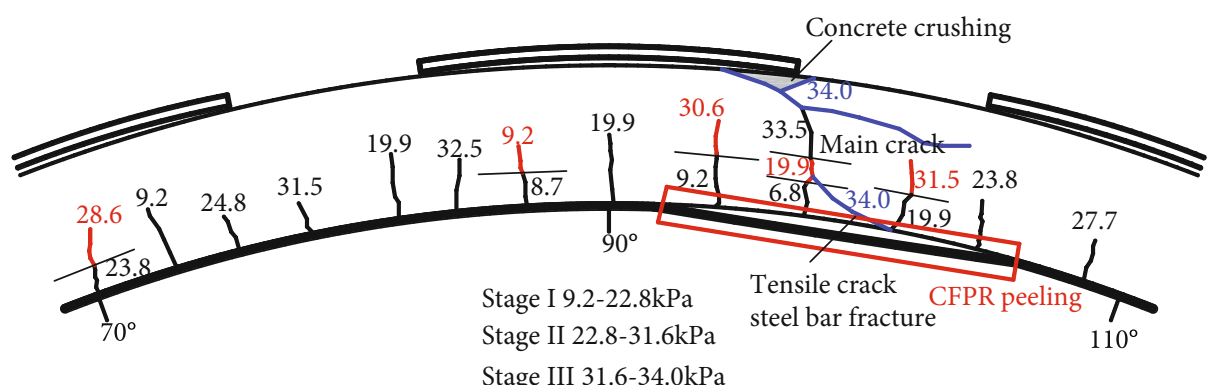

(d) Near $90^{\circ}$ in the vault

FIgURE 9: Fracture distribution of the lining under condition 3.

It should be noted that the stiffness, deformation, and cracking load of a structure are very different when strengthened at different damage states. The earlier the strengthening is conducted, the greater the stiffness of the strengthened structure is, and the more effectively the deformation is controlled. Compared with the stiffness $K_{\text {II }}$ prior to cracking, the stiffness $k_{\mathrm{I}}$ of compatible deformation stage I after strengthening increases by $501 \%, 171 \%$, and $126 \%$ for condi- tions 2, 3, and 4, respectively. At rapid deformation stage II after strengthening, compared with the stiffness $K_{\mathrm{II}}$ prior to cracking, the stiffness $k_{\mathrm{II}}$ increases by $76 \%, 5 \%$, and $18 \%$ for conditions 2, 3, and 4, respectively. At the time of failure, the vault settlement under condition 2 , where the strengthening was conducted earlier, reached $12.58 \mathrm{~mm}$, which is only $74 \%$ and $70 \%$ of the vault settlement for conditions 3 and 4 . Thanks to the earlier strengthening under condition 2 , the cracking 


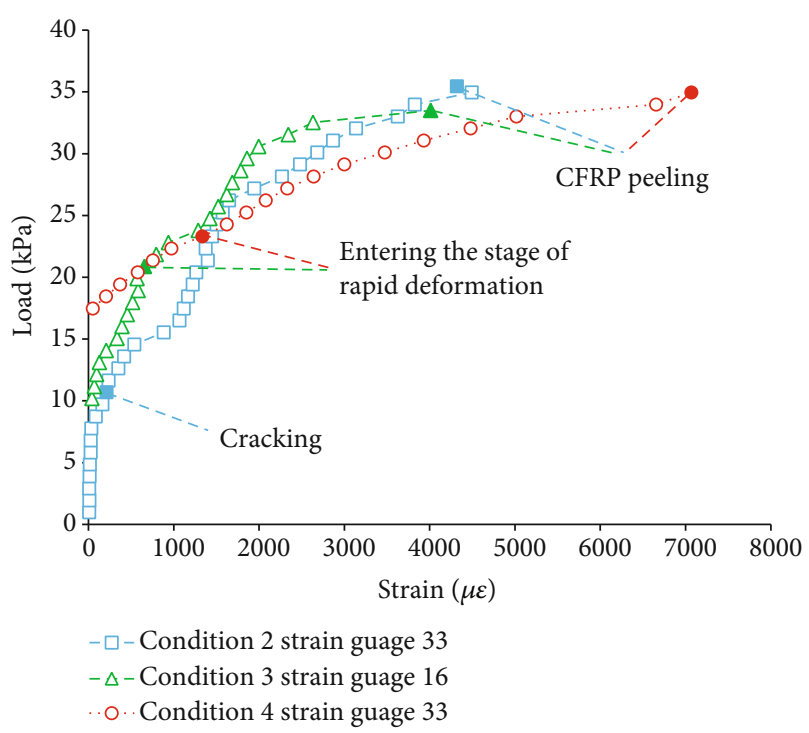

FIgURE 10: Curves of load-strain with strengthening.

TABle 4: Comparison of statistics for different conditions.

\begin{tabular}{lcccc}
\hline Condition & 1 & 2 & 3 & 4 \\
\hline$P_{c}$ & 6.8 & 10.7 & 6.8 & 5.8 \\
$P_{r}$ & - & 0 & 9.2 & 16.5 \\
$P_{u 0}$ & 18.9 & - & - & - \\
$P_{u}$ & - & 35.4 & 34.0 & 35.0 \\
$P_{u} / P_{u 0}$ & - & 1.87 & 1.79 & 1.85 \\
$K_{\mathrm{II}}$ & 1.55 & - & - & - \\
$k_{\mathrm{I}}$ & - & 9.32 & 4.21 & 3.51 \\
$k_{\mathrm{II}}$ & - & 2.74 & 1.63 & 1.83 \\
$w$ & 14.40 & 12.58 & 16.90 & 17.91 \\
$s$ & 14.37 & 20.22 & 23.55 & 24.63 \\
\hline
\end{tabular}

load of the arch increased from $6.8 \mathrm{kPa}$ to $10.7 \mathrm{kPa}$, which is $57 \%$ higher than that of the original structure.

Therefore, although the timing of the strengthening has an insignificant effect on the load-carrying capacity, early strengthening is preferred whenever possible in order to ensure the tunnel clearance height.

\section{Conclusions}

In this paper, a 1:10 scaled model was tested in order to study the failure characteristics of reinforced concrete lining, as part of the highway tunnels constructed in grade VI surrounding rock strengthened using CFRP sheets at different damage states and subjected to a secondary load. Based on the test data of the scaled model, the deformation and failure processes of the strengthened structures were obtained. The test data were converted using the similitude ratios of the prototype tunnel structure. The characteristics of the reinforced concrete lining structures in the grade VI surrounding rocks and the CFRP-strengthened structures under loads are summarized as follows.
(1) Under the loose load, the deformation and failure processes of the original reinforced concrete lining structure can be divided into three stages, namely the elastic and crack-free stage, the operational but cracking stage, and the accelerated instability stage. The failure is after the successive fracture of the vault and the hances on both side of the arch, with the vault as the controlling section

(2) Under the secondary load, the deformation and failure processes of the CFRP-strengthened structures are divided into three stages, which are the compatible deformation stage, the rapid deformation stage, and the accelerated instability stage. The failure of the hances is affected by the vault, which is the key structural section, and thus, the strengthening design should be based on the ultimate load-carrying capacity of the vault

(3) The improvement of the failure load after CFRP strengthening at different damage states is essentially the same. However, the earlier strengthening contributes to a better control of structural deformation. Therefore, if the arch clearance is limited, strengthening should be carried out as soon as possible

(4) Once the CFRP sheets peel off, the structural fragments fall off quickly and the tunnel collapses. Therefore, the effectiveness of CFRP bonding should be guaranteed in real-world engineering projects. In addition, the peeling of the CFRP sheets can be used as a criterion for evaluating the failure of the strengthened structures

\section{Data Availability}

All data, model, and code generated or used during the study appear in the submitted article are available from the corresponding author upon request.

\section{Conflicts of Interest}

The authors declare that there is no conflict of interest regarding the publication of this paper.

\section{Acknowledgments}

This study was supported by the National Basic Research Program of China (973 Program) [grant number 2015CB057806], the National Natural Science Foundation of China [grant numbers 51878497], and the Major Science and Technology Special Projects of Guizhou Science and Technology Department [grant number 黔科合重大专项 字[2018]3011].

\section{References}

[1] F. H. Administration, Tunnel Operations, Maintenance, Inspection and Evaluation (TOMIE) Manual, U.S. DOT, Washington, 2013. 
[2] A. Inokuma and S. Inano, "Road tunnels in Japan: deterioration and countermeasures," Tunnelling and Underground Space Technology, vol. 11, no. 3, pp. 305-309, 1996.

[3] J. A. Richards, "Inspection, maintenance and repair of tunnels: International lessons and practice," Tunnelling and Underground Space Technology, vol. 13, no. 4, pp. 369-375, 1998.

[4] H. L. Wang, X. Z. Liu, N. Li, and D. W. Xie, "Safety evaluation of tunnel lining with longitudinal cracks and reinforcement design," Chinese Journal of Rock Mechanics and Engineering, vol. 29, Supplement 1, pp. 2651-2656, 2010.

[5] F. H. Administration and F. T. Administration, Highway and Rail Transit Tunnel Maintenance and Rehabilitation Manual, Military Bookshop, Washington, 2004.

[6] L. N. Luo, Research on the calculation method of CFRP strengthened highway tunnel lining, Tongji University, Shanghai, 2006.

[7] Y. J. Li, H. J. Xu, Y. Zhang, and J. J. Yao, "Application of carbon fiber cloth in reinforcement of metro tunnel disease," Applied Mechanics and Materials, vol. 353-356, pp. 1525-1528, 2013.

[8] L. Jia and H. B. Nie, "Study of mechanical properties of freezing-thawing damaged concrete bending components of tunnel strengthened by CFRP sheets," Tunnel Construction, vol. 36, no. 7, pp. 819-825, 2016.

[9] W. Li, W. Gang, Z. Dong, and S. Wang, "Experimental study on a pre-damaged scaled tunnel model strengthened with CFRP grids," Journal of Southeast University (English Edition), vol. 33, no. 2, pp. 196-202, 2017.

[10] H. Sahranavard and R. Aghanoori, "Use of new technology in repair and renovation of Haji Abad tunnel," Tunnelling and Underground Space Technology, vol. 21, no. 3-4, pp. 319-319, 2006.

[11] Y. J. Jiang, Y. Tanabashi, M. Fujii, X. D. Zhao, and S. Idenaga, "Database development for road tunnel maintenance and management by using geographical information system," Soil Mechanics \& Foundation Engineering, vol. 52, pp. 25-27, 2004.

[12] S. W. Park, Y. S. Shin, Y. S. Oh, and S. R. Ahn, "A guideline on condition assessment of existing old railway tunnels," Tunnelling and Underground Space Technology, vol. 21, no. 3-4, pp. 329-330, 2006.

[13] N. S. Kim, J. H. Lee, and S. P. Chang, "Equivalent multi-phase similitude law for pseudodynamic test on small scale reinforced concrete models," Engineering Structures, vol. 31, no. 4, pp. 834-846, 2009.

[14] X. L. Lu, G. K. Fu, W. X. Shi, and W. S. Lu, "Shake table model testing and its application," Structural Design of Tall and Special Buildings, vol. 17, no. 1, pp. 181-201, 2008.

[15] M. Ramu, V. P. Raja, and P. R. Thyla, "Establishment of structural similitude for elastic models and validation of scaling laws," KSCE Journal of Civil Engineering, vol. 17, no. 1, pp. 139-144, 2013.

[16] B. Chen, S. C. Zhang, Y. Y. Li, Z. K. Li, and H. J. Zhou, "Physical simulation study of crack propagation and instability information discrimination of rock-like materials with faults," Arabian Journal of Geosciences, vol. 13, p. 966, 2020.

[17] J. T. Chen, J. H. Zhao, S. C. Zhang, Y. Zhang, F. Yang, and M. Li, "An experimental and analytical research on the evolution of mining cracks in deep floor rock mass," Pure and Applied Geophysics, vol. 177, no. 11, pp. 5325-5348, 2020.

[18] C. Zhu, M. He, M. Karakus, X. Cui, and Z. Tao, "Investigating toppling failure mechanism of anti-dip layered slope due to excavation by physical modelling," Rock Mechanics and Rock Engineering, vol. 53, no. 11, pp. 5029-5050, 2020.

[19] Z. G. Tao, Y. Shu, X. J. Yang, Y. Y. Peng, Q. H. Chen, and H. J. Zhang, "Physical model test study on shear strength characteristics of slope sliding surface in Nanfen open-pit mine," International Journal of Mining Science and Technology, vol. 30, no. 3, pp. 421-429, 2020.

[20] E. Winkler, Theory of Elasticity and Strength, H Dominicus, Prague, 1867. 